\title{
O uso do tempo no cotidiano de mulheres idosas: um método indicador do estilo de vida de grupos populacionais
}

\author{
Time use in the daily life of aged women: \\ an indicative method of the life style of population groups
}

Leonice Aparecida Doimo ${ }^{1}$

Alice M oreira Derntl ${ }^{2}$

Olival Cardoso do Lago ${ }^{3}$

${ }^{1}$ Departamento deEducação Física, U niversidade Federal deViçosa. Avenida Peter Henry Rolfs $s / n$, Campus Universitário. 36570-000 Viçosa M G. ladoimo@ufv.br

${ }^{2}$ Faculdade deSaúde Pública, Universidade de São Paulo.

${ }^{3}$ Escola Superior de Educação Física de Jundiaí.
Abstract Time use research analyzes the multifactorial aspects of aging. The purpose of this re search was to describe time use within a group of 75 elderly women, 68,04 \pm 8,36 years old, based on their daily activities from waking up to going to sleep. The instruments used in the study werea cognition test (Clock Completion Test), a questionnaire for obtaining personal data and structured interviews (Time Diary) for obtaining information about the activities carried out on the day prior to the interview. The daily activities were decoded and classified by means of an international classification for time use studies, thus obtaining the profiles of the daily activities assigned to nine groups of main activities and their physical and social contexts. It was verified that the greater part of time was spent with mandatory activities (housework and personal care). M ost of the free time was spent with passive leisure (TV watching) and little physical activity. Most of the activities were performed at home (physical context), and the elderly women used to live either with members of their family or alone (social context). Individual factors such as age, gender, educational level, marital status and socioeconomic level probably play a role in the time use patterns found.

Key words Time use, Aging, Elderly
Resumo 0 estudo do uso do tempo considera a heterogenei dade do envel hecimento, analisandoo multifatorialmente, permitindo vislumbrar o estilo de vida de indivíduos idosos. Este estudo objetivou descrever o uso do tempo de 75 idosas (68,04 $\pm 8,36$ anos), através das suas atividades diárias. Instrumentos utilizados: teste de cognição (Clock Completion Test), formulário para dados pessoais e entrevista estruturada (Time Diary) para relato das atividades diárias. Para decodificação e classificação das atividades diárias, utilizou-se a classificação australiana para estudos de uso do tempo, distribuindo-as em nove grupos de atividades principais. Foram verificados os contextos físico (local) e social (parceiros sociais) das atividades. Verificou-se que grande parte do tempo destinou-se às atividades obrigatórias (atividades domésticas e de cuidados pessoais). A maior proporção do tempo livre destinou-se ao lazer passivo (assistir televisão) com pouco envolvimento em atividades físicas. A casa e estar com membros da família ou sozinhas re presentaram o contexto físico e social mais pre sentes. 0 estudo permitiu um vislumbre do estilo de vida do grupo. Provavelmente houve influência defatoresindividuais como idade, gênero, grau de instrução, estado civil e nível socioeconômico sobre os padrões en contrados para o uso do tempo. Palavras-chave U so do tempo, Envelhecimento, Idoso 
Introdução

0 grande contingente de indivíduos idosos é o maior usuário dos serviços de saúde, consumindo parte considerável de seus recursos e do orçamento governamental destinado a este setor ${ }^{1}$. Assim, as perspectivas para o novo milênio implicam adotar medidas preventivas para que a maior parcela possível de idosos desfrute a vel hice em mel hores condições de saúde e bem-estar, procurando mantê-los autônomos em relação àssuas capacidadesfísica, psicológica, social, econômica e afetiva, condições essas essenciais para um envelhecimento bem-sucedido? .

Atualmente, vem se destacando na gerontologia o estudo do uso do tempo que, diferentedo binômio saúde-doença e das escalas de capacidade funcional, permite considerar a heteroge neidade do envelhecimento, com resultados que podem ser direcionados para a adoção de medidas preventivas a serem aplicadas à população idosa ou subgrupos dela ${ }^{3-7}$. 0 valor da informação sobre o uso do tempo reside no fato de queo tempo é um recurso fundamental e não renovável, igualmente partilhado, pois todos possuem as mesmas vinte e quatro horas num dia. Assim, a medida do uso do tempo pode tornar-se uma unidade internacional, podendo ser usada em diferentes culturas para quantificar os tipos, a duração, a seqüência e a coordenação das atividades humanas. A partir de uma análise lógica de atividades e comportamentos de uso do tempo, são identificadas três dimensões inseparáveis para a relação tempo-atividade: 1) a própria atividade ou ação, significando o comportamento observável; 2) onde ela é realizada, significando o local ou contexto físico e 3) na presença de quem ela é realizada, significando a interação ou contexto social ${ }^{8}$. Com base nesta análise, propôs-se uma tipologia, composta de quatro categorias de tempo: 1) tempo necessário, utilizado na execução de cuidados pessoais; 2) tempo contratado, relacionado com as atividades de emprego e educação regular; 3) tempo comprometido, relacionado às atividades obrigatórias (trabal ho doméstico, cuidados com os familiares, adquirindo bens e serviços, trabalho não remunerado fora de casa) e 4) tempo livre (atividades religiosas, culturais, cívicas, sociais, esportes e demais atividades de lazer), tempo que permanece após a exclusão dos três primeiros tipos. É importante observar que lazer é al go subjetivo e pessoal, pois muitas atividades incluídas na categoria de tempo comprometido podem ser consideradas como atividades de lazer.
Estudos de uso do tempo com idosos podem ser utilizados para verificar uma ampla gama de aspectos do envel hecimento, dentre eles a possibilidade de captar mudanças nos model os deatividade ao longo do tempo, os quais podem fornecer informações valiosas sobre o bem-estar do idoso e seu estilo de vida, para uso no desenvolvimento de ambientes sociais adequados ${ }^{9}$. Sob esta perspectiva, pesquisadores ${ }^{3}$ avaliaram o uso do tempo como um indicador de competência comportamental e bem-estar psicológico e, o que émais importante, respeitando elevando em consideração os efeitos das limitações funcionais na execução das atividades cotidianas. Para esses autores, o modo como o indivíduo utiliza seu tempo possui uma variedade de determinantes, incluindo oportunidades ambientais, personalidade, eventos particulares e saúde funcional, fazendo-os considerar o uso do tempo como um indicador de estilo de vida de uma pessoa ou grupo. Portanto, a descrição da estruturação da vida diária dos idosos, em função do uso do tempo, e a influência de outras variáveis (idade, sexo, escolaridade, renda, por exemplo) sobre o engajamento nas atividades cotidianas, fornecem um primeiro vislumbre sobre a competência diária destes indivíduos, reflete diferenças em termos de estilos de vida e pode fornecer a chave para a melhoria na qualidade de vida desta população, na medida em que aponta para possíveis áreas que demandem necessidade de intervenção, visando retardar o aparecimento de agravos que poderiam pôr em risco a autonomia e independência destes indivíduos ${ }^{10,11}$.

Assim, tendo o tempo como referência, realizou-se um estudo com o objetivo de descrever a forma de uso do tempo de um grupo de mulheres idosas para realização de suas atividades cotidianas, destacando-se o local onde estas atividades acontecem (contexto físico) equais parceiros (contexto social) estão presentes durante a realização das mesmas.

Método

Participantes

Foram entrevistadas 75 mulheresidosas, pertencentes a grupos de convivência de uma Unidade Básica de Saúde da cidade de São Paulo, caracterizando, metodologicamente, uma amostra de conveniência selecionada pelo critério de acessibilidade ${ }^{12}$.

Após esclarecimentos, todas que aceitaram 
fazer parte do estudo assinaram um termo de consentimento livre eesclarecido.

Participaram do estudo mulheres fisicamente independentes, com 60 anos e mais, com função cognitiva preservada. A presença de doenças crônicas não foi considerada, uma vez que idosos podem adaptar-se às mesmas, podendo levar uma vida autônoma e independente ${ }^{13}$.

\section{Instrumentos}

$\mathrm{Na}$ entrevista individual, previamente agendada, foram aplicados, pela ordem, os seguintes procedimentos:

a) The Clock Completion Test para avaliar a capacidade cognitiva, sendo os escores do teste utilizados como critério de inclusão/exclusão no estudo ${ }^{14}$. Todas as participantes obtiveram escores normais no referido teste;

b) formulário para registro de dados pessoais, com os seguintes campos: dados de identificação (nome, idade, estado civil); grau de instrução; ocupação (anterior e atual); tipo e valor de benefício recebido; residência (com quem reside, quantas pessoas residem na casa, tipo de propriedade);

c) Time Diary, para registro das atividades diárias recordadas, desde o acordar até o deitar$\mathrm{se}^{8}$. Para classificar as atividades diárias mencionadas, utilizou-se a classificação australiana de atividade de uso do tempo ${ }^{15}$.

Sobre o Time Diary

e a classificação das atividades diárias

O Time Diary é um tipo de diário com perguntas estruturadas que, em pesquisas de uso do tempo, é deixado com o participante para que o mesmo vá anotando todas as atividades que realiza, desde o acordar atéo momento de deitar-se, registrando-as, em geral, em interval os de cinco, dez ou quinze minutos. Pode-se também aplicálo sob forma de "recordatório", onde o indivíduo rememora as atividades real izadas no dia anterior. 0 instrumento apresenta cinco campos com as seguintes perguntas: Qual a atividade principal?, Para quem a atividadefoi feita?, Quetipo de atividade fazia ao mesmo tempo? (atividade secundária), Onde você estava? (contexto físico) e Quem estava com você? (contexto social).

Para classificar (organizar) todas as atividades mencionadas no diário, adota-se uma classificação, constituída, em geral, por nove ou dez grupos principais de atividades ou grupos primários que, juntos, englobam todos os aspectos da atividade humana: 1 - cuidados pessoais; 2 emprego/ocupação formal; 3 - atividades educacionais; 4 - atividades domésticas; 5 - atividades de cuidados com crianças; 6 - aquisição de bense serviços; 7 - trabalho voluntário; 8 - atividades sociais; 9 - recreação e lazer. Por sua vez, cada grupo principal engloba uma série de atividades relacionadas, em níveis mais detalhados e variados, podendo até existir subgrupos de atividades secundárias. Esta variedade de atividades tornase responsável pelas diferenças entre as classificações existentes, e faz-se necessária porque deve contemplar atividades específicas da cultura de um país ou população e atividades das quais se deseja obter um conhecimento mais apurado. As atividades do grupo principal são codificadas com um dígito, atividades secundárias com dois dígitos esubdivisões de uma mesma atividade secundária recebem três dígitos. Como exemplo, citase um item da classificação neozelandesa, onde a participação em atividades religiosas, culturais e cívicas (grupo principal) tem como dígito/código o número 8. A participação em cerimônias ou rituais específicos da cultura maori recebe o dígito/código 83 (atividade secundária). As viagens associadas à participação em cerimônias ou rituais específicos da cultura maori recebem o dígito/ código 838 (subdivisão de atividade secundária). Em estudos de uso do tempo, atividades não recordadas também devem ser consideradas para efeito de tabulação dos dados.

Neste estudo, todas as atividades mencionadas foram direcionadas para um dos nove grupos de atividades principais da classificação australiana. Portanto, utilizou-se a mesma somente no seu nível mais simples de classificação (um dígito), não utilizando o instrumento em toda sua complexidade. A freqüência das atividades (número de vezes que são mencionadas) realizadas em cada grupo foi multiplicada pelo intervalo de tempo de registro no diário (neste trabaIho, cinco minutos), obtendo-se assim o tempo consumido na realização das mesmas. 0 somatório do tempo dos grupos principais de atividades dividido pelo número de participantes forneceu a média do dia efetivo, ou seja, o espaço compreendido entre 0 acordar e o deitar-se.

Pelo fato de pessoas idosas poderem apresentar dificuldades motoras ou visuais, impedindo um registro adequado das atividades, foi realizada uma entrevista recordando-se todo o dia anteriormente vivenciado, permitindo também a interven ção do entrevistador no sentido de auxiliar no processo recordatório, possibilitando a inclusão de atividades que podem ser esquecidas 
devido à tendência da pessoa em fixar-senas atividades que foram mais significativas durante 0 dia. 0 método recomenda que sejam descartadas entrevistas incompletas, que evidenciem informações equivocadas, ou que reconstituam menos da metade do dia e, ainda, aquelas cuja maior parteéfornecida por acompanhantes, caso estejam presentes.

N esteestudo, na coleta, foi solicitado que cada idosa recordasse todos os eventos do dia anterior, desde o despertar até o deitar-se. Este procedimento objetivou obter informações sobre 0 primeiro campo do Time Diary, ou seja, saber "qual a atividade principal". A entrevistadora anotou todas as informações e, após ter todas as atividades listadas na devida seqüência e a duração em que foram mencionadas, leu cada atividade em voz alta e solicitou à entrevistada que mencionasse para quem a atividade foi feita, 0 que mais fazia ao mesmo tempo (atividade secundária), local onde a atividade foi realizada (contexto físico) equem estava presente durante a atividade (contexto social). Este procedimento permitiu a adição de atividades que poderiam ter sido esquecidas pelo fato de não serem consideradas relevantes.

Em decorrência do volume substancial das informações, o Time Diary foi definido recordando-se apenas um dia da semana por idosa. Levantar e deitar-se foram considerados início e fim do recordatório e não foram consideradas atividades para efeito de inserção nos grupos principais de atividades. Às idosas solicitou-se recordar atividades realizadas de segunda à sexta-feira (portanto, as entrevistas realizaram-se somente de terça a sábado), presumindo-se que, durantea semana, o leque deatividades seria mais amplo. N enhuma entrevista foi descartada e todas as informações foram fornecidas pelas próprias entrevistadas. A duração de todo o procedimento girou em torno de 45 a 60 minutos para cada idosa.

Para efeito devalidação da classificação, considerou-se a validade lógica ${ }^{16}$ para estudos dessa natureza.

Tipos de trabal ho, atividades de lazer e contextos físico e social

Dentre os grupos principais de atividades, optou-se por dar maior importância aos grupos deemprego/ocupação erecreação elazer, no sentido de severificar quais eram as ocupações exercidas e também em quais tipos de atividades 0 lazer era vivenciado. Foram também verificados os contextos físico (locais de realização de atividades) e social (pessoas presentes quando da realização das atividades) do grupo.

\section{Análise dos dados}

Os resultados dos dados pessoais e da distribuição do tempo entre os nove grupos principais de atividades foram analisados em termos depercentuais. 0 mesmo procedimento foi adotado para tipo de trabal ho remunerado eatividades de lazer. Os resultados foram discutidos sob forma de tendências observadas. Os cálculos foram efetuados através do programa S-Plus ${ }^{17}$.

\section{Resultados}

A idademédia do grupo foi de 68,04 anos $( \pm 8,36)$. Quanto ao estado civil, 33 eram casadas (44\%), trinta, viúvas (40\%), nove, desquitadas (12\%) e três, solteiras (4\%).

Em relação ao grau de escolaridade das entrevistadas, nove idosas (12\%) distribuíram-se entre ter cursado a primeira e segunda série do antigo curso primário, 48 (64\%), entre a terceira equarta série, seis ( $8 \%$ ) cursaram entre aquinta esexta série do primeiro grau e doze (16\%), entre a sétima e oitava série. N enhuma cursou 0 antigo curso colegial.

Vinte e sete idosas (36\%) disseram não receber nenhum tipo de benefício ou remuneração e 24 delas (32\%) afirmaram receber até um salário mínimo. A maioria (sessenta idosas) informou ter exercido apenas a atividade de dona de casa até os 60 anos. Após esta idade, 51 idosas (68\%) dedicavam-se apenas às atividades da casa e 24 (32\%), além dos cuidados domésticos, exerciam atividades remuneradas, porém, sem registro em carteira. Quanto à moradia, todas residiam em imóvel próprio, sendo que dezoito moravam sozinhas, 36, com uma pessoa (marido ou filho) e 21, com mais de uma pessoa.

A distribuição do tempo entre os nove grupos principais de atividades é apresentada na Tabela 1 eFigura 1. Em média, para cada idosa, 0 dia efetivo foi de 16h20'. Dentre os grupos, o mais preponderante foi o de atividades domésticas (33\%), seguido pelo grupo de recreação elazer (26\%). N este último, observa-se que grande parte do tempo destinado à recreação e lazer foi utilizado para assistir televisão (47\%) e atividades como prática deexercícios eesportes eleitura não foram expressivos (Figura 2). Os grupos de atividades de cuidados pessoais e emprego/ocu- 
pação consumiram 16\% e 14\% do dia efetivo, respectivamente. As atividades de emprego, sem registro em carteira, foram as seguintes: vendas domiciliares (oito idosas), empregada doméstica e confecção deartesanato (sete idosas em cada atividade), cozinheira (duas idosas). Ressalta-se que o exercício da maioria destas ocupações se dava conforme disponibilidade de horários. 0 grupo que incluiu atividades sociais nos seus relatos ocupou apenas 6,3\% do tempo efetivo.

o contexto físico mostrou que o principal ambiente de realização das atividades diárias ocorre no próprio domicílio (74\%), seguido de outros locais privados, representados pela residência de amigas ( $13 \%$ ). Quando dicotomizado em atividades realizadas dentro efora de casa, o con-

Tabela 1. Freqüência das atividades, distribuição do tempo e porcentagem do dia efetivo em relação aos grupos principais de atividades.

\begin{tabular}{lccc}
\hline \multicolumn{1}{c}{ Grupos principais de atividades } & Freqüência das atividades $^{*}$ & M inutos & \% do dia efetivo \\
\hline 1 - Cuidados pessoais & 2.373 & 11.865 & 16,2 \\
2 - Emprego/ocupação & 2.016 & 10.080 & 14 \\
3 - Atividades educacionais & 00 & 00 & 00 \\
4 - Atividades domésticas & 4.830 & 24.150 & 33 \\
- Cuidados com crianças & 39 & 195 & 0,2 \\
6 - Aquisição de bense serviços & 246 & 1.230 & 1,7 \\
7 - Trabalho voluntário/cuidados & 93 & 465 & 0,6 \\
8 - Atividades sociais & 930 & 4.650 & 6,3 \\
9 - Recreação e lazer & 3.768 & 18.840 & 26 \\
Atividades não recordadas & 291 & 1.455 & 2 \\
TOTAL & 14.586 & 72.930 & 100 \\
\hline
\end{tabular}

*número devezes queas atividades foram mencionadas a cada intervalo de cinco minutos.

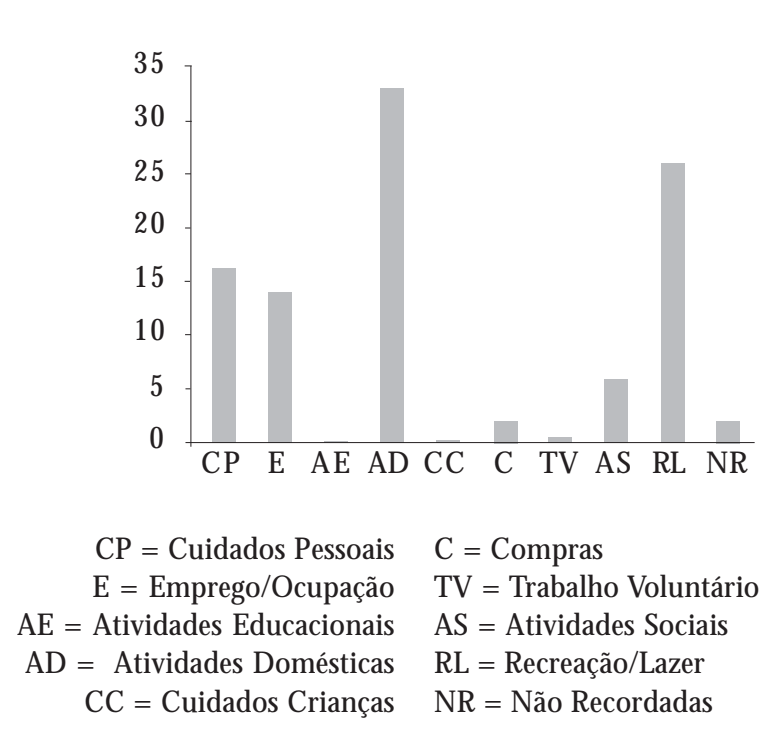

Figura 1. Distribuição porcentual dos grupos principais de atividades em relação ao dia efetivo.

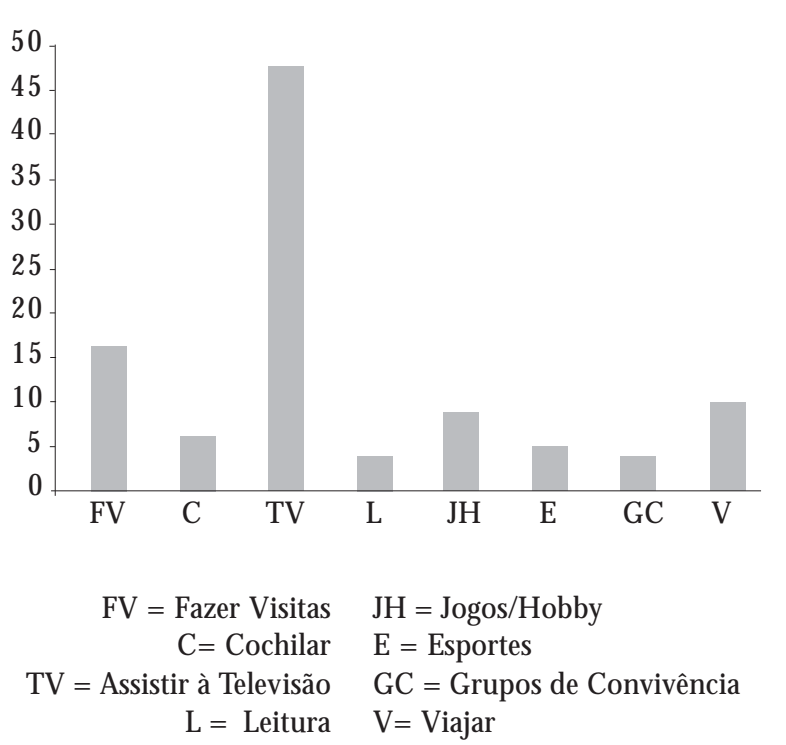

Figura 2. Distribuição porcentual das atividades de lazer e recreação. 
texto físico mostra $74 \%$ das atividades realizadas no ambiente doméstico enquanto somente $24 \%$ fora dele.

0 contexto social, conforme Figura 3, mostra que a maior parte do dia efetivo das idosas (47\%) passou-se na companhia de parentes (fiIhos, irmãs, primas, cunhadas), sozinhas ( $28 \%$ ) ou na companhia do marido (15\%). Quando categorizado em estar só e estar acompanhada, observa-se que $28 \%$ das atividades foram realizadas a sós e $70 \%$ na presença de um ou mais parceiros sociais.

\section{Discussão}

Em relação às características pessoais, a maioria das idosas enquadra-se na descrição de alguns autores, ou seja, baixa escolaridade, baixa renda econômica e, em grande parte, residindo sozinhas. Assim, o somatório destas desvantagens pode se refletir na qualidade de vida destas idosas, levando-as a um maior número de situações de fragilidade e limitação social 1, 2,18.

Como mencionado, o estudo do uso do tempo éuma medida do espaço psicológico e social, podendo ser avaliado como indicador compor-

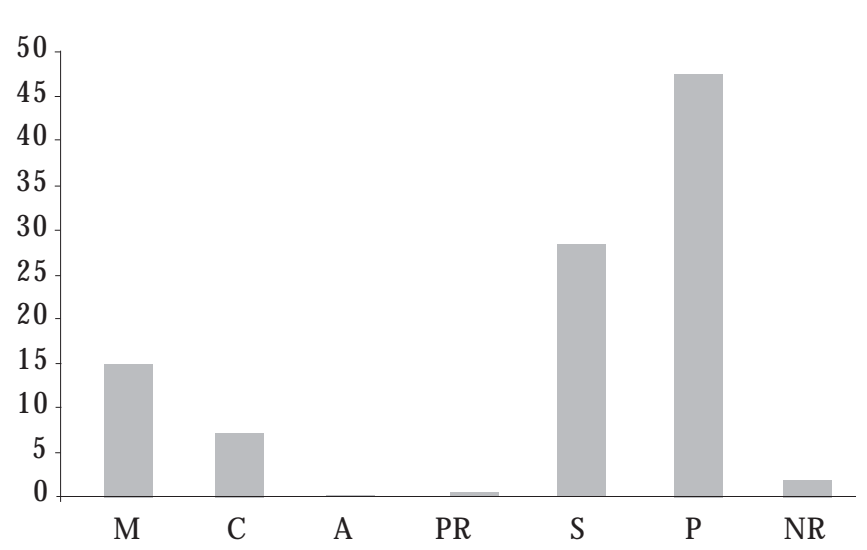

$$
\begin{array}{ll}
M=M \text { arido } & P R=\text { Profissionais } \\
C=\text { Crianças } & S=\text { Sozinha } \\
A=\text { Amigos } & P=\text { Parentes } \\
& N R=\text { Não Recordo }
\end{array}
$$

Figura 3. Distribuição porcentual do contexto social das atividades diárias. tamental, ou seja, indicador de estilo de vida, sendo o comportamento competente um dos fatores determinantes de tal estilo ${ }^{3}$. Assim, a análise dosgrupos principais deatividades evidenciou que estas se distribuíram, em maior proporção, em atividades obrigatórias - conjunto de atividades básicas ${ }^{19}$ e instrumentais ${ }^{20}$ - ou seja, a maior parte do dia efetivo das mulheres idosas pesquisadas foi direcionada para a execução de atividades necessárias a uma adequada manutenção do viver, tanto do ponto de vista fisiológico quanto do aspecto organizacional do ambiente, representados pelos grupos de atividades domésticas e cuidados pessoais, indicando amplo estado de autonomia e independência deste grupo. A estas atividades obrigatórias somou-se, para algumas mulheres, uma ocupação de caráter produtivo, como medida econômica complementar, constituindo-se, também, em oportunidades de novas experiências fora do próprio ambiente doméstico.

O fluxo de atividades mostrou que o tempo gasto na realização deatividades domésticas ocupou predominantemente as manhãs, enquanto atividades de cuidados pessoais foram distribuídas de modo mais ou menos uniforme ao longo do dia. Já as atividades de lazer concentraram-se no período da tarde, evidenciando que as opções pelas atividades discricionárias ocorrem após 0 cumprimento de atividades ditas essenciais. Diante da possibilidade de reorganizar as tarefas cotidianas em termos de prioridades, em virtude de uma nova dinâmica de vida resultante da viuvez e ou dos filhos encaminhados, o fato de as atividades domésticas serem o grupo de maior freqüência pode ser indicativo da herança cultural, própria dessa geração, onde à mulher cabia o papel de encarregada do trabal ho de manutenção, enquanto ao homem recaía o papel produtivo, impondo assim um atributo de gênero para as tarefas domésticas, com uma reprodutibilidade sistemática de tal comportamento.

Os resultados também mostraram que parte do tempo foi destinado à atividades de lazer ou recreação, um grupo que engl oba a grande maioria das atividades denominadas discricionárias ${ }^{3}$, escolhidas pela própria pessoa e caracterizadas por envolver afeto, conhecimento, prazer, interesse e por sofrerem influência de inúmeros fatores como idade, cognição e nível socioeconômico. A ausência dos filhos e a viuvez podem ser fatores responsáveis por maior parcela de tempo livre, já quehá diminuição deresponsabilidades epreocupações domésticas. Lazer pode significar tempo para investir no desenvolvimento pessoal sendo, no entanto, um ideal quasesemprenão concretiza- 
do. 0 tempo livre é em grande parte consumido na forma de lazer passivo, principalmente assistir à tel evisão, o que foi constatado neste estudo. Um dos motivos para ocupação do tempo livre com lazer passivo pode significar solidão, pois pessoas solitárias e insatisfeitas com vários aspectos de suas vidas podem vir a preencher seu tempo livre com estetipo de atividade, ou seja, não encontrar satisfação e motivação em determinados aspectos da vida podedirecionar as experiências cotidianas para atividades pouco exigentes e dinâmicas. 0 fato do lazer ativo não ocupar maior proporção do tempo livre das idosas estudadas também pode ser atribuído a aspectos individuais, culturais e falta de oportunidades adequadas de interação e aprimoramento pessoal oferecidas pela própria comunidade. Porém, para al gumas pessoas, muitas vezes o que se considera trabal ho podeser interpretado como lazer ativo, pois estas encontram em tais atividades um desafio significativo que exige empenho ehabilidadee, portanto, encontram prazer em executá-las.

Um dos fatores que pode acelerar o declínio funcional da pessoa idosa diz respeito à inatividade física ${ }^{21,22}$. 0 pouco envolvimento do grupo estudado em atividades físicas durante o lazer torna-se preocupante, na medida em que o exercício regular vem sendo apontado como tendo importante papel no aprimoramento da qualidade de vida, na redução de agravos e da mortalidadee na manutenção da independência. Embora não se tenha a comprovação de que o exercício aumente a expectativa de vida, a atividade física exerce um importante papel no aprimoramento da qualidade de vida das pessoas ${ }^{23}$. M uitas das alterações na estrutura fisiológica enafunção orgânicaqueocorrem com o envelhecimento resultam do não envolvimento em atividadesfísicas adequadas ${ }^{24}$. Essa desatenção se refletirá, em maior ou menor grau, no nível de dependência da pessoa idosa, definindo principalmenteseu grau deindependência para realizar as atividades da vida diária, pois impedimentos de mobilidade são fortes preditores de mortalidade e dependência dessa população 25,26 . Comportamentos adequados à promoção da saúde por parte da população idosa, especialmente exercíciosenutrição adequada, podem constituirse em fatores críticos para a manutenção da independência pelo maior tempo possível, postergando a necessidade de intervenções por parte do sistema de saúde, já que são fatores que podem retardar o início de processos incapacitantes ${ }^{27}$.

Com relação ao trabalho, constatou-se que vinte e quatro idosas exerciam atividades remuneradas, sem registro em carteira, visando prin- cipalmente à complementação da renda familiar. Embora possa ser um fardo pesado, o trabalho podeter suas compensações. Dentre elas, segundo se apurou nas entrevistas, ter um trabalho pode significar um encorajamento à concentração e um elo mais efetivo com o mundo, eliminando em grande partepensamentosesentimentos negativos. Quando em casa, com familiares ou sozinhas, sem uma ocupação, muitas pessoas carecem de um sentido claro para suas vidas, muitas vezes sentindo que suas habilidades estão sendo subutilizadas, o que pode gerar sentimentos de negatividade e inferioridade. Para as pessoas idosas, ter um trabalho considerado essencial, por ela e pelos outros, agrega sentimento de valor e integração ao contexto de suas famílias.

Em termos de espaço físico, os resultados mostram que a vida cotidiana tem lugar em vários ambientes distintos. Além das atividades e das companhias, o espaço físico também tem efeito sobrea qualidade com que se vivencia o dia-adia. Adultos talvez prefiram espaços que permitam a expressão da sua individualidade de forma mais natural. Por exemplo, atividades realizadas fora de casa podem significar um alívio da rotina diária e oportunidade de novas e diferentes interações. Por outro lado, deve-se considerar que o próprio ambiente doméstico, muitas vezes, se constitui no espaço de predileção única e que seus diferentes setores podem apresentar um perfil emocional peculiar porque cada um édestinado à execução de atividades diferentes, podendo gerar sensações também diferentes. Assim, é de se esperar que muitas mulheres idosas se sintam seguras e confortáveis usufruindo integralmente do seu ambiente doméstico, o que pode ser evidenciado pela alta porcentagem de atividades realizadas na própria casa. Estes resultados revelam comportamento semel hante ao apontado por outros autores ${ }^{28}$, que mencionam uma proporção maior de atividades realizadas no ambiente doméstico, mostrando a sua influência na distribuição das atividades em relação ao contexto do ambiente físico da pessoa idosa. Os resultados encontrados também foram semelhantes a estudo anterior ${ }^{4}$, que evidenciou maior proporção de atividades realizadas no ambiente doméstico, fazendo deste espaço o domínio geográfico por excelência na vida diária do idoso, principalmente da mulher.

Outra característica principal da vida cotidiana do idoso éa possibilidade de entrar e sair do estado de solidão, ou seja, alternar o contexto social das atividades, já que o cotidiano não é somente definido por aquilo quesefaz, mas tam- 
bém por aqueles que se fazem presentes durante a ação, de modo que pessoas vivem períodos de tempo distribuídos em contextos sociais semeIhantes, formados pela família, estranhos, amigos ou então, sós. A família forma o contexto social em princípio de maior segurança, onde se estabelecem laços de proximidade e responsabilidademútuos. N esteestudo, a família, eespecialmente o marido, representaram os parceiros sociaismaisfreqüentes, um relacionamento importante para o suporte do idoso, pois pode prover uma troca permanente de assistência entre seus membros. Estar só, o segundo contexto social mais presente entre as idosas, implica um modo de vida a ser aprendido, pois muitas vezes estar só não se constitui numa opção e sim algo "adquirido" eadaptar-seéde suma importância para a própria qualidade de vida. A solidão, aliada à ausência de atividade ou a uma atividade rotineira, pode ocupar a mente com pensamentos de primentes, pois não há objetivo válido no qual concentrar a atenção, além de comprometer a motivação, a concentração, a auto-estima e levar a uma seqüência de estados negativos como passividade, apatia e distanciamento. Pode-se supor que tal quadro se apresente com maior freqüência entre pessoas com menores recursos materiais e educacionais e entre solteiras ou viúvas.

Já o tempo partilhado com amigos ou outras pessoas foi muito menor em relação a outros parceiros sociais. Embora seja o tipo de relacionamento que permite um maior crescimento individual, dado que os acontecimentos resultantes da interação com os outros podem ser dos mais imprevisíveis, possíveis explicações poderiam ser que, neste tipo de situação, as exigências relacionais seriam maiores, impondo, talvez, o medo da rejeição pelo outro ou então a dificuldade em permitir a criação de um espaço para acolher o outro, juntamente com suas diferenças. Relacionar-se melhora a qualidade de vida porque possibilita encontrar naquele com quem se partilha os problemas um estímulo eum referencial de apoio emocional. A falta de amigos verdadeiros torna as relações mais efêmeras e superficiais, podendo tornar-se um aspecto negativo na vel hice, já que poderá interferir diretamente na rede de suporte social, onde o amparo ou alguma assistência à pessoa idosa, por parte de pessoas próximas, podenão ser possível. Neste sentido, um aspecto fundamental do envelhecimento bem-sucedido é a necessidade de manter relacionamentos verdadeiros com outras pessoas, pois a qualidade dos mesmos pode influir diretamente na saúde física e mental ${ }^{29}$.
Finalizando, ao contrário das escalas de atividades básicas e instrumentais da vida diária, que avaliam a pessoa idosa com base na investigação de parâmetros relacionados com competências, estetipo de estudo permitiu identificar a heterogeneidade do universo ocupacional de mulheres idosas, respeitando as distintas experiências do envelhecimento.

Assim, a partir da identificação e categorização das atividades cotidianas e do levantamento do elenco das atividades que se constituem em fonte de maior prazer e realização, épossível implementar interven ções, col etivas ou personalizadas, com o objetivo de diversificar os padrões de atividades com a finalidade de melhorar significativamente o bem-estar da pessoa idosa. Do ponto de vista pessoal, o primeiro passo para atuar sobre a qualidade da vida cotidiana consiste em organizar e reestruturar as atividades diárias, de modo a extrair delas as experiências mais recompensadoras porque, para se atingir um crescimento verdadeiramentereal, segundo o referencial do envelhecimento bem-sucedido ${ }^{29}, 30$, é necessário o engajamento em atividades que sejam interessantes e estimulantes.

É fundamental, também, que se realize uma abordagem mais qualitativa, atribuindo mais importância às características sociais, culturais, econômicas e afetivas das pessoas idosas, para se compreender melhor os comportamentos e realizar as intervenções possíveis e necessárias de modo a orientar uma melhor qualidade de vida para as mesmas.

Quando realizada de forma simples e com grupos menores, esta modalidade de estudo permite um diagnóstico mais rápido eespecífico do ambiente e do estilo de vida dos grupos populacionais, possibilitando ajustar as intervenções e recursos que são possíveis e que se encontram disponíveis à realidade da própria comunidade, implantando-os em curto prazo. Como exemplo, neste estudo verificou-se a participação reduzida em atividades sociais, podendo indicar que al gumas das idosas se encontram num quadro de isolamento social. Da mesma forma, a baixa participação em atividades físicas poderá implicar limitações nos níveis de independência dessas mulheres. 0 próximo passo seria buscar compreender o motivo para tais comportamentos e quais as formas e meios disponíveis para possíveis mudanças atitudinais. As alternativas podem ser buscadas simultaneamente, dentro do próprio grupo, através da orientação e estímulo (empowerment) para o autocuidado e dentro da comunidade na qual a pessoa está inserida. 


\section{Conclusões}

O método utilizado permitiu visualizar o cotidiano de um grupo de mulheres idosas, obtendo-se uma indicação do seu estilo de vida, bem como ambiente físico e parceiros sociais presentes durantea realização das suas atividades diárias, possibilitando desenhar um panorama do universo biopsicossocial das mesmas e, ao mesmo tempo, respeitando suas limitações e distintas trajetórias de vida. Provavelmente houve influência de fato- res individuais como idade, gênero, grau de instrução, estado conjugal e nível socioeconômico nos padrões encontrados para o uso do tempo. Complementarmente, quanto às ações programáticas possíveis, o método apontou para a viabilidade de um direcionamento efetivo para possíveis intervençõese, se real izado sistematicamente, para a possibilidade de acompanhamento das tendências e trajetórias do envelhecimento de e entre mulheres de diferentes gerações e níveis socioeconômicos ao longo do tempo.

\section{Colaboradores}

LA Doimo trabalhou na concepção, pesquisa, metodologia e redação final; AM Derntl trabaIhou na concepção do trabalho; OC Lago trabaIhou na metodologia e tabulação dos dados.

\section{Referências}

1. Chaimowicz F. Os idosos brasileiros no século XXI demografia, saúde e sociedade. $1^{\text {an }}$ ed. Belo Horizonte: Postgraduate; 1998.

2. Sayeg MA. Envelhecimento bem sucedido e 0 autocuidado: algumas reflexões. Arq Geriatr Geront 1998; 2(3):96-98.

3. Moss M S, Lawton M P. Time budgets of older people: a window on four lifestyles. J Gerontol 1982; 37(1):115-123.

4. Baltes M M, Wahl HW, Furstoss S. The daily life of elderly Germans: activity patterns, personal control, and functional health. J Gerontol. [resumo na Internet]. 1990. [acessado 2004 Jan 03]. Disponível em: http://www.ncbi.nlm.gov/entrez/query

5. Wahl HW. Everyday competence: a construct in search for an identity. Z Gerontol Geriatr 1998; 31(4):243-249.

6. Horgas $A L$, Wilms HU, Baltes MM. Daily life in very old age: everyday activities as expression of successful living. Gerontologist 1998; 38(5):556-568.

7. Albert SM. Time and function. In: Rubistein RL, Moss M, Kleban MH, editors. The many dimensions of aging. New York: Springer Publishing Company; 2000. p.57-67.

8. Stinson LL. M easuring how people spend their time: a time-use survey design. M onthly Labor Review 1999; 122:12-19.

9. Ujimoto KV. Time-budget methodology for research on aging. Social Indicators Research 1990; 23:381-393.

10. Willis SL. Everyday cognitive competence in elderly persons: conceptual issues and empirical findings. Gerontologist 1996; 36:595-601. 
11. Diehl M. Everyday competence in later life: current status and future directions. Gerontologist 1998; 38(4):422-433.

12. Polit DF, Hungler BP. Nursing research: principles and methods. $3^{\text {rd }}$ ed. Philadelphia: Lippincott Company; 1989.

13. Kirkwood T. Os melhores anos de nossa vida. Rio de Janeiro: Editora Record; 2001.

14. Watson YL, Arfken CL, Birge SJ. Clock completion: an objective screening test for dementia. J Am Geriatr Soc 1993; 41(11):1235-1240.

15. Australian Bureau of Statistics. Time use survey, Australia. Confidentialist unit record file (information paper). Canberra: Australian Bureau of Statistics; 1997. [ABS Catalogue $n=4151.0$ ]

16. Goode WJ, Hatt PM. M étodos em pesquisa social. 4a ed. São Paulo: Companhia Editora Nacional; 1973.

17. S-Plus 4. Guide to Statistics [computer program]. Seattle: M athsoft/ Data Analysis Products Division; 1998.

18. Berquó E. Algumas considerações demográficas sobre o envelhecimento da população no Brasil. Seminário Internacional sobre o Envelhecimento Populacional: uma agenda para o fim do século, 1996 Junho 1-3; Brasília, Brasil.

19. Lawton MP, Brody EM. Assessment of older people: self maintaining and instrumental activities of day living. Gerontologist 1969; 9:179.

20. Verbrugge LM, Gruber-Baldini AL, Fozard JL. Age differences and age changes in activities: Baltimore longitudinal study of aging. J Gerontol Psychol Sci Soc Sci 1996; 51(1):S30-41.

21. Daley MJ, Warwick L. Exercise, mobility and aging Sports M edicine 2000; 29(1):1-12.
22. M atsudo SM, M atsudo VKR, Barros N eto TL. Impacto do envelhecimento nas variáveis antropométricas, neuromotoras e metabólicas da aptidão física. Rev Bras Ciên e M ov 2000; 8(4):21-32.

23. Blain $H$, Vuillemin $A$, Blain $A$, Jeandel $C$. The preventive effects of physical activity in the elderly. Presse M edicale 2000; 29(22):1240-1248.

24. Pescatello LS, DiPietro L. Physical activity in older adults - an overview of health benefits. Sports M ed 1993; 15(6):353-364.

25. M oura RN, Santos FC, Driemeier M, Santos LM, Ramos LR. Quedas em idosos: fatores de risco associados. Gerontologia 1999; 7(2):15-21.

26. Hirvensalo $M$, Rantanen $T$, Heikkenen E. Mobility difficulties and physical activity as predictors of mortality and loss of independence in the community-living older population. J Am Geriatr Soc 2000; 48(5):493-498.

27. Woo J. Relationships among diet, physical activity and other lifestyle factors and debilitating diseases in the elderly. Eur J Clin Nutr 2000; 54(Suppl 3): S143-147.

28. Bennett KM. Gender and longitudinal changes in physical activities in later life. Age Aging 1998; 27:24-28.

29. Volz J. Successful aging: the second 50. Monitor on Psychology [periódico on line]. 2000 [acessado 2005 Set 13]; 31 (1): [cerca de 4 p.]. Disponível em: http:/ /www.apa.org/monitor/jan00/homepage.html

30. Rowe JW, Kahn R. Human aging: usual and successful. Science 1987; 237:143-149.

Artigo apresentado em 07/02/2006

A provado em 24/10/2006

Versão final apresentada em 02/07/2007 